\title{
Some Morphological Observations on the Thoracic Limb Bones of the Hairy-nosed Wombat (Lasiorhi- nus latifornis, Owen)
}

\section{A.S.Saber*}

*Faculty of Veterinary Medicine, University of Sadat City, Sadat City, Egypt \& School of Veterinary and Biomedical Sciences, James Cook University, Townsville, Australia.

\section{Abstract}

In this study, one Wombat (Lasiorhinus latifornis) was used to describe the bones of the thoracic limb. It was observed that the fossa supraspinata was nearly equal to the fossa infraspinata. The Processus hamatus and processus suprahamatus were present and processus coracoideus was well developed. Tuberculum majus was divided into cranial and caudal parts. A proximally directed pointed process arising from the caudal border line of the humerus was described as well as a supracondylar foramen. The radius and ulna are separated bones with welldeveloped lateral and medial processus styloideus.

Four proximal and two distal ossa carpi and five metacarpals were determined.
The results were discussed with other domestic and wild mammals and supported with $10 \mathrm{im}$ ages.

Keywords: Hairy-nosed wombat, thoracic limb skeleton, bones

\section{Introduction}

The wombat is a nocturnal marsupial that digs burrows and be active at night (Beatty, 1972). It is about 1 meter long from nose to tail, the tail being only a couple of centimeters long. An adult weighs about 25-35 kilograms. Wombats are the largest burrowing mammals. They belong to the Order: Diprotodontia, Suborder: vombati-formes, Family: Vombatidae (fig 1). They are stocky animals with short, stout limbs, a short neck, a massive broad, 
dorso-ventrally flattened skull and a large broad sacrum. They are plantigrade with short foreand hind legs of approximately equal length (Wells, 1984).

As there is no precise anatomical description of the musculoskeletal system of the wombat in general and its skeleton in special could be found in the available literatures, this study was carried out, trying to fill this gap in studying the anatomy of the wombat.

\section{Material and Methods}

A male wombat (Lasiorhinus latifornis krefftii) kept in the freezing room in the Discipline of Anatomy and Pathology, School of Veterinary and Biomedical Sciences, James Cook University (JCU), Townsville, Australia was used in this study. After evisceration and dissection for the anatomy comparative practical, the animal bones were cleaned by boiling, de-fattening, bleaching and air dried. Then after, the bones of the thoracic limb were described, photographed with a Samsung digital camera (WB700). The results were compared with the relevant in other small-sized, domestic and wild animals.

\section{Results}

The first observation of the bones is that they are quite different in shape comparing with those of the small sized domestic species like dogs, cats and rabbits. The bones are short and very massive.

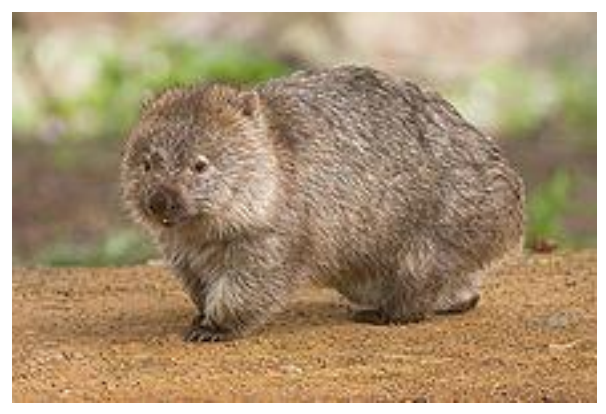

Fig (1): The hairy-nosed wombat (source: Wikipedia)

\section{I) Scapula (fig 2)}

Is a flat bone, about $13 \mathrm{~cm}$ long and $4.5 \mathrm{~cm}$ wide. The cranial border (Margo cranialis) makes a hump-shaped elevation, followed by deep concavity, the neck (Collum scapulae). The proximal part of this elevation bears four small projections and its distal part ends at the supraglenoid tubercle (Tuberculum supraglenoi-dale) which is connected to the oval 
shaped coracoids process (Processus cora-coideus). The scapular spine (Spina scapulae) is about $3 \mathrm{~cm}$ high and $11.5 \mathrm{~cm}$ long and curves distally, lateroventrally forming the acromion which possesses the Processus hamatus and Processus suprahamatus. and metacromion process and articulating with the clavicle forming acromio-clavicular joint. The spine divides the lateral surface into Fossa supraspinata and Fossa infra-spinata with the ratio nearly $1: 1$. The nutrient foramen lies in the supraspinous fossa, at the neck of the bone, about $3 \mathrm{~cm}$ proximal to the supraglenoid tubercle. The Fossa supraspinata is triangular in shape, while the Fossa infraspinata is rather long oblong. The glenoid cavity (Cavitas glenoidalis) is oval in shape (about $3 \mathrm{~cm}$ long and $2 \mathrm{~cm}$ wide) and is connected with the supra-glenoid tubercle with a ridge of bone. The subscapular fossa (Fossa subscapularis) is deep, long and is parallel to the caudal border (Margo caudalis). The Facies serrate is a deep triangular area below the caudal angle. The cranial and caudal angles (Anglulus cranialis and Angulus caudalis) are very thick. A second nutrient foramen is found on the medial surface at the level of the neck.

\section{II) Clavecle (Fig 3)}

Is a long bone, about $8 \mathrm{~cm}$ long and flattened lateraomedially. Its proximal tapering extremity articulates with the scapula and the distal wide extremity articulates with the sternum. The lateral surface of the distal extremity represents a deep oval furrow with many differents sized foramina (Fig 3/A).

\section{III) Humerus (Fig 4,7).}

Humers is a long bone, measures about $10.5 \mathrm{~cm}$ long. The head (Caput humeri) is rounded and of about $2.5 \mathrm{~cm}$ diameter and larger than the glenoid cavity of the scapula. The neck (Collum humeri) is distincit caudally. The major tubercle (Tuberculum majus) is curved and is divided by a ridge into a large craniolateral part (pars cranialis) and a smaller caudal part (pars caudalis). Its crest (Crista tuber-culi majoris) is rounded and is about the same level of the head. The lesser tubercle (Tuberculum minus) is small and faces cranio- 
medially. The intertuberal space bears many foramina of different sizes.

The deltoid tuberosity is very prominent (about $2.5 \mathrm{~cm}$ long), and has a pointed lip at its middle. The musculospiral groove (Sulcus $\mathrm{m}$. brachialis) is deep, wide and brings the caudal surface cranially. The teres major tuberosity (Tuberositas teres major) is very prominent elevation on the lateral surface and reaches $2.5 \mathrm{~cm}$ long.

The distal half of the humerus body (Corpus humeri) have two characteristic features; the first is the proximally directed pointed process on the line of the caudal border forming a deep concavity with it. The second is the large elongated suprachondylar foramen (Foramen supera-condylar) which is about $12 \mathrm{~mm}$ long, and situated above the medial epicondyle (Epicondylus medialis) (Fig 4/C).

The medial epicondyle is very large and massive, while the lateral epicondyle (Epicondylus lateralis) is smaller. The lateral condyle is rounded and larger than the medial one. The Fossa coronoidalis is thin and triangular in shape (Fig 4/A).

\section{Radius (Fig 5,7,8)}

The radius is a long bone, reaches $10 \mathrm{~cm}$ in length. It is smaller in size than the ulna which seems to be the major bone of the antebrachium. It articulates with the small articular surface on the lateral proximal part of the Facis cranialis of the ulna. The Corpus radii is triangular in cross section, possesing cranial, caudal and lateral surfaces. The cranial surface have a distincitive ridge on its distal half. The distal part of the Corpus radii is wider than its proximal one. It bears the carpal articular surfaces and the lateral styloid process (Processus styloideus medialis) which is longer and more pronounced than the medial one.

\section{Ulna (Figs 6,7,8)}

The ulna is a long bone, about $13.5 \mathrm{~cm}$ long and $3 \mathrm{~cm}$ wide at the level of the Incisura trochlearis. The olecranon tuber (Tuber olecrani) bears small triangular process medially, while the anconeous process (Processus anconeus) is directed laterally and encroaches the 
lateral area of the incisura trochlearis which articulates with the lateral condyle of the humerus. The medial surface of the incisura is a shallow oval in outline, about $2 \mathrm{~cm}$ long and is adapted for articulation with the medial condyle of the humerus The head of the ulna (Caput ulnae) bears the articular surface with the carpal bones, as well as the small medial styloid process (Processus styloideus lateralis) . The ulna forms with the radius the proximal and distal interosseous spaces (Spatium interosseum antebrachii proximale et distale).

\section{Carpal Bones (Fig 9)}

There are 6 carpal boses in the wombat arranged in two rows. The proximal row is formed of radial, intermediate, ulnar and accesory carpal bones. The distal row consists of only two bones.

\section{Metacarpal Bones (Fig 10)}

The manus is complete with five digits and there are five distincit metacarpal bones lying between the carpal bones and phalanges. The comparative lengths of the metacarpal bones are in the IV, Mc V and Mc I which is the shortest. There are two palmar sesamoid bones in pairs at each of the metacarpo-phalangeal joints except that of the fist digit which posses only one sesamoid bone.

\section{Digits (Fig 10)}

There are three phalanges in all the five digits. In each digit, the proximal and middle phalanges articulate with each other forming the proximal interphalangeal joint, while the middle and distal articulate forming the distal interphalangeal joint. The distal phalanges of all digits are arched and pointed to accommodate the curved nails. In passing downwards the digits diverge slightly.

\section{Discussion}

The scapula of the wombat, in addition to the acromion process presented the metacromion (hamate) process. The metacromion process has been also reported in the African giant rat by Olawoye et al. (2011) and in other Rodentia species (Hebel and Stromberg, 1976; Özkan, 1997), 
in carnivorous animals (Sisson and Grossman, 1975; Nzalak et al., 2010). It was only in the cat and rabbit that the suprahamate process reported (Dyce, 2002; Al-Hussaini and Demian, 1964) respectively. Özkan (2002) observed that the fossa infraspinata (46\%) was larger than fossa supraspinata $(39 \%)$ in the mole-rat. On the contrary, Yilmaz et al., (1998) described in porcupine the fossa supraspinata as larger than the fossa infraspinata (54.7\% \& $45.3 \%$ respectively). Olude et al. (2010) noticed the same in the African giant rat, while Olawoye et al. (2011) mentioned that the scapula spine divided the lateral surface almost equally in the same rat species. Both fossae were also equal in size in the wombat of this study.

Olawoye et al. (2011) mentioned that the presence of clavicle in $C$. gambianus is a common feature of the rodent family. It is one of the characteristic of a burrowing animal (Greene, 1968). Its presence has been reported in the guinea pig (Wagner and Mannyng, 1976), rabbit (Uçar et al., 1985) and mole rat (Özkan, 2002) as well as in the wombat of this study.
The presence of a prominent deltoid tuberosity in wombat as well as in African giant rat (Olawoye et al., 2011) agreed with what was reported for the Muridae family (Saunders and Manton, 1969; Çalitlar, 1978; Özkan, 2002). The distal extremity of the rat's humerus presented supracondylar (supratrochlear) foramen similar to what was reported for cats (Dyce et al., 2002), in rabbit (Al-Hussaini and Demian, 1964) and in the wombat of this study. The proximally directed pointed process arising from the caudal border line in the wombat was not described in any other animal species compared with in this study.

Radius and ulna presented no significant difference from the typical mammalian bones. Contrary to what Olude et al. (2009) reported in the African giant rats and Özkan (2002) in the mole-rat that the two bones were not fused in some of their specimens, Olawoye et al. (2011) described fused radius and ulna in the same species. The presence of styloid process at the distal end of these two bones resembled what was reported in dog and cat (Miller, 1964; Dyce et al., 
2002) in porcupines Yilmaz et al. (1998).

Hyett and Shaw (1980) mentioned that the manus of the hairy-nosed wombat is 5-toed, palm is naked and coarsely granulated, pads are not well defined, claws are long strong. Digits 2 and 3 syndactylous with long claws, 4 and 5 are free and long-clawed. It walks on palm and sole. Wells (1984) confirmed walking of the wombats on the sole of their feet. He added that the forefeet have five forward facing digits with strong flattened claws. Same results were observed in this study. However, the aforementioned authors did not give more details on the carpals, metacarpals and phalanges of the digits.

Olawoye et al. (2011) reported that the number and arrangement of the manus in the African giant rat was typical of the Rodentia order (Saunders and Manton, 1969; Demy'rsoy, 1997, 1998) and agreed with the work of Greene (1968) on the albino rat. In rabbit, Al-Hussaini and Demian (1964) described five metacarpals and mentioned that the digits have a digital formula
2:3:3:3:3. Yilmaz et al.(1998) in porcupines and Özkan (2002) in mole-rat described also five meta-carpals. Hughes and Dransfield (1953) reported as well, on five metacarpals in the dog. They mentioned that the first is much the shortest and the third and fourth are the longest, while the fifth is the thickest bone of the five. The same authors mentioned that the most medial digit possesses only two phalanges, one properly representing the fused first and second phalanges, the other are the third phalanx. They affirmed that the medial digit does not come in contact with the ground like the other four. In the wombat all the digits contact the ground and the first (most medial) one have three phalanges.

The arched and pointed shape of the distal phalanges as observed in this study and reported for the hind limb are for easy burrowing and shoveling, an opinion mentioned by (Olude et al., 2009, 2010) which I also agree with.

Olawoye et al. (2011) in the African giant pouched rat mentioned that the arrangement of the carpal bones into two rows with the 
number of bones in the proximal row being four and in the distal row five. This finding agreed with what was reported in other mammals such as horse, pig, dog, cat and ruminants (Sisson and Grossman, 1975).In porcupine (Yilmaz et al., 1998) mentioned four proximal and four distal ossa carpi. In the mole-rat, Özkan (2002) and in the African giant rat (Olude et al., 2010) described two bones in the proximal row; the fused radial and intermediate and ulnar bones and four bones in the distal row namely I, II, III, IV, in addition to os carpi centrale distal to the intermedioradial bone. In the wombat of this study there were 4 bones in the proximal and 2 in the distal row.

In rabbit, Al-Hussaini and Demian (1964) mentioned that the carpus consists of 9 bones: a proximal row of 3 bones, a radial (scaphoid) articulates with the radius, an intermedium (lunar) and an ulnar (cuneiform) articulates with the ulna. A (centrale) bone in the center and the distal row of 4 bones, the $1^{\text {st }}$ carpal (trapezium), and $2^{\text {nd }}$ carpal (trapezoid), the $3^{\text {rd }}$ carpal (os magnum), and the fused $4^{\text {th }}$ and $5^{\text {th }}$ carpals (unciform). In addition, a small bone (pisiform) caudomedial to the carpus is present and articulates with the ulna and ulnar carpal bone.

Hughes and Dransfield (1953) described 7 carpal bones in both dog and cat, three in the proximal row and four in the distal row. They added that the reduction in the number of bones commonly present in the proximal row is due to the fusion of scaphoid (radial) and lunate (intermedium) bones forming a single large bone which articulates with the radius. Moreover, on the caudo-medial aspect of the dog's carpus a small shot-like sesamoid bone is usually articulated with the scapho-lunate (radiointermediate) bone.

\section{Conclusion}

- $\quad$ There are some prominent features in the thoracic limb bones of the hairnosed wombat (Lasiorhinus latifornis) as a burrowing and shoveling mammal.

- The ridges and tuberosities on the bones are very well developed and 
denoting strong muscle attachment.

\section{Acknowledgement}

I would like to thank Mrs Kerry Johns, the technician of the Discipline of Anatomy and Pathology, School of Veterinary and Biomedical Sciences, JCU for her fine work done for preparing the limb skeleton used in this study.

\section{References}

Al-Hussaini, A., H. and Demian, E.S. (1964): Practical animal biology, Vol. II, Systematic zoology, $2^{\text {nd }}$ ed. Dar Al-Maaref, Cairo, Egypt.

Bill Beatty (1972): Unique to Australia. Ure Smith, Sydney.

Çalitlar T (1978): Laboratuvar Hayvanlary' Anatomisi. Fy'rat Üniv. Vet. Fak. Yay. 14, Ankara Ün. Basy'mevi, Ankara, pp. 106123.

Demy' Rsoy A (1998): Yay' amy'n Temel Kurallary'. Meteksan AT, Ankara, pp. 33-76.
Demy'Rsoy A (1997): Türkiye Omurgaly' lary'. Memeliler, Meteksan AT, Ankara, pp. 83-105

Dyce KM, Sack WO, Wensing CJG (2002): Veterinary Anatomy. WB Saunders Company, Philadelphia, 3: 76-81.

Greene CE (1968): The anatomy of the rat: Transactions of the American Philosophical Society. New Series. Hafner Publishing Company, New York, London. gross anatomisi üzerinde incelemeler. Fırat Ün Sag Bil Derg, 27(11): 171-175.

Hebel R, Stromberg M (1976): Anatomy of the laboratory rat. Williams and Wilkins Company, Baltimore, MD., pp. 106-132

Hughes, H.V. and Dransfield, J.W. (1953): McFadyean's Osteology \& Arthrology of the domesticated animals. Bailliere, Tindall and Cox, London.

Hyett, J. and N. Shaw (1980): Australian Mammals. A field guide for New South Wale, Victoria, South Australia \& Tasmania. Thomas Nelson, West Melbourne, Australia. 
J. Arthur Thomson, M.A., L.L.

D. (1916): Outlines of Zoology (New York, NY: D. Appleton \& Company, 1916)

Miller ME (1964): The Anatomy of the Dog. W.B. Saunders Co. Philadelphia, pp. 64-78.

Nzalak JO, Eki MM, Sulaiman MH, Umosen AD, Salami SO, Olude MA, Olopade JO, Akinloye AK, Mustapha OA (2010): Macro-anatomical investigations of the skeletons of the African giant rat (Cricetomys gambianus Waterhouse): Forelimb. Eur. J. Anat., 14: 19-23.

Matthew A. Olude, James 0. Olopade, Adebayo. K. Akinloye and Oluwaseun A. Mustapha (2010): Macro-anatomical investigations of the skeletons of the African giant rat (Cricetomys gambianus Waterhouse 1840) II: Fore limb. Eur J Anat, 14 (1): 1923 (2010)

Olude MA, Olopade JO, Mustapha OA (2009): Macro-anatomical investigations of the skeletons of the African giant rat (Cricetomys gambianus Waterhouse): Pelvic limb. Eur. J. Anat., 13: 127-131.
Özkan ZE (2002): Macroanatomical investigations on the forelimb skeleton of mole rat (Spalax leucodon Nordmann). Vet. Arhiv.72: 91-99.

Özkan ZE, Dinç G, Aydin A (1997): Tavsan (Oryctolagus cuniculus) kobay (Cavia porcellus) ve ratlarda (Rattus norvegicus), scapula, clavicula, skeleton brachii ve skeleton antebrachii'nin karsılastırmalı

Parker, T. Jeffrey (1900): $A$ Manual of Zoology, New York, NY: The MacMillan Company.

Sadik Yilmaz, Z. Ender Özkan, Dervis Özdemir (1988): MacroAnatomical Investigations on the Skeletons of Porcupine (Hystrix Cristata) I. Ossa Membri Thoracici Tr J Vet Anim Sci, 22:389392

Saunders JT, Manton SM (1969): A manual of practical vertebrate morphology. Clarendon Press, Oxford, 4: 208-286.

Sisson and Grossman (1975): The anatomy of the domestic animals, 88-177. Edited by R. Getty W.S. Saunders co. 
Uçar Y, Öcal M, Haziroglu M (1985): Makro-anatomische Untersuchungen über die Clavic-ula des einheimischen Hundes, der einheimischen Katze und Neuzelandshasens.J.Fac.Vet.Med.U niv.Ankara, 32:42-52.

Wagner JE, Manning PJ (1976): The Biology of the Guinea Pig. Academic Press, New
York, San Francisco, London, 10-44.

Wells, R.T. (1984): Southern Hairy-nosed Wombat Lasiorhinus krefftii. P.120 in Strahan, R. (ed.) The Australian Museum Complete Book of Australian Mammals. The National Photographic Index of Australian Wildlife. Angus \& Robertson: Sydney.

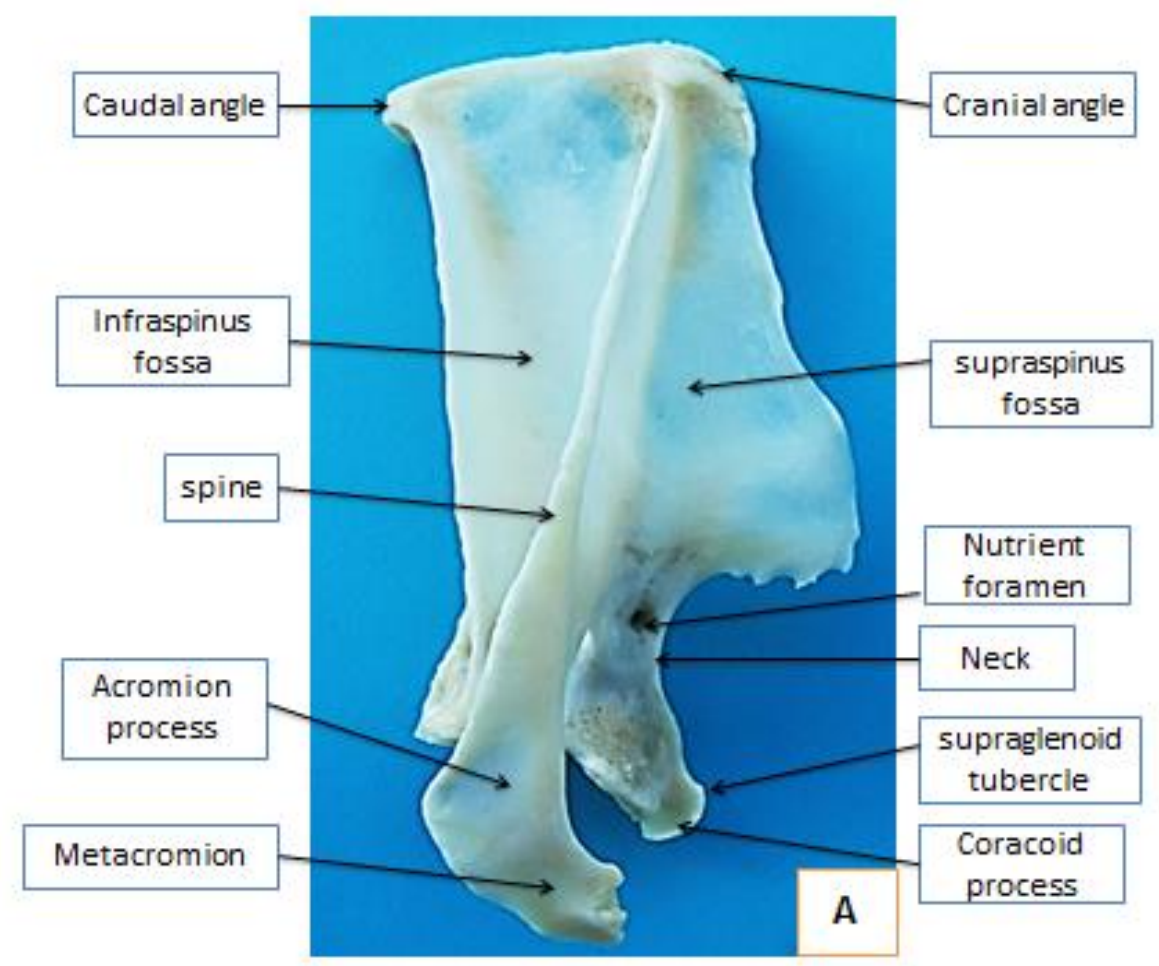

Fig (2): Scapula of Wombat; A) Lateral view. 


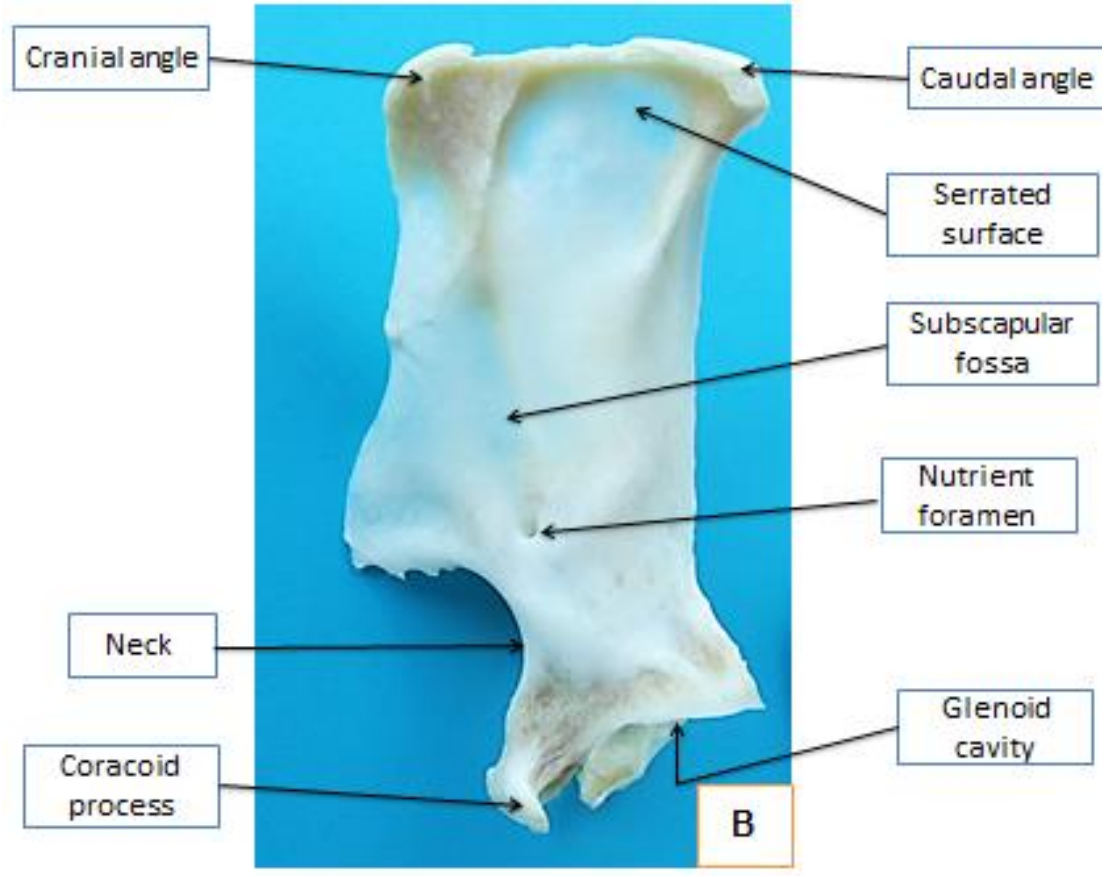

Fig (2): Scapula of Wombat; B) Medial view

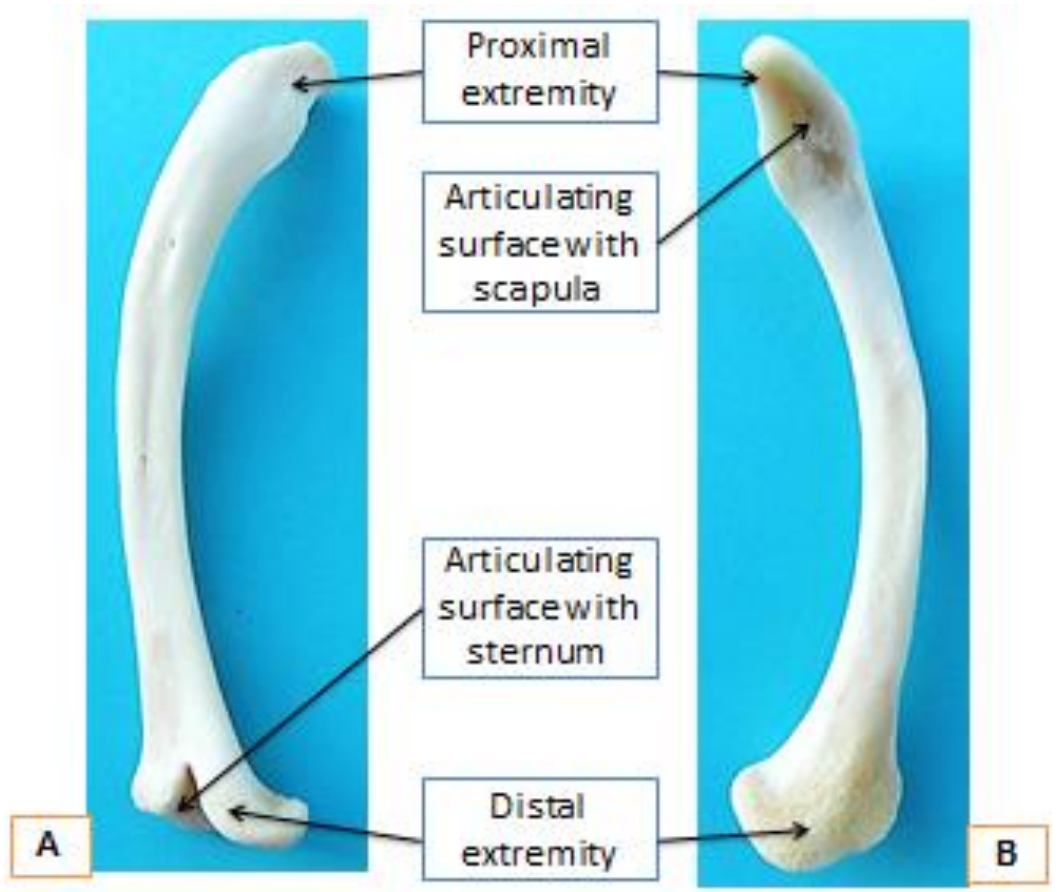

Fig (3): Clavecle of Wombat; A) Lateral view, B) Medial view 
Thoracic limb bones of Wombat

A. S. Saber

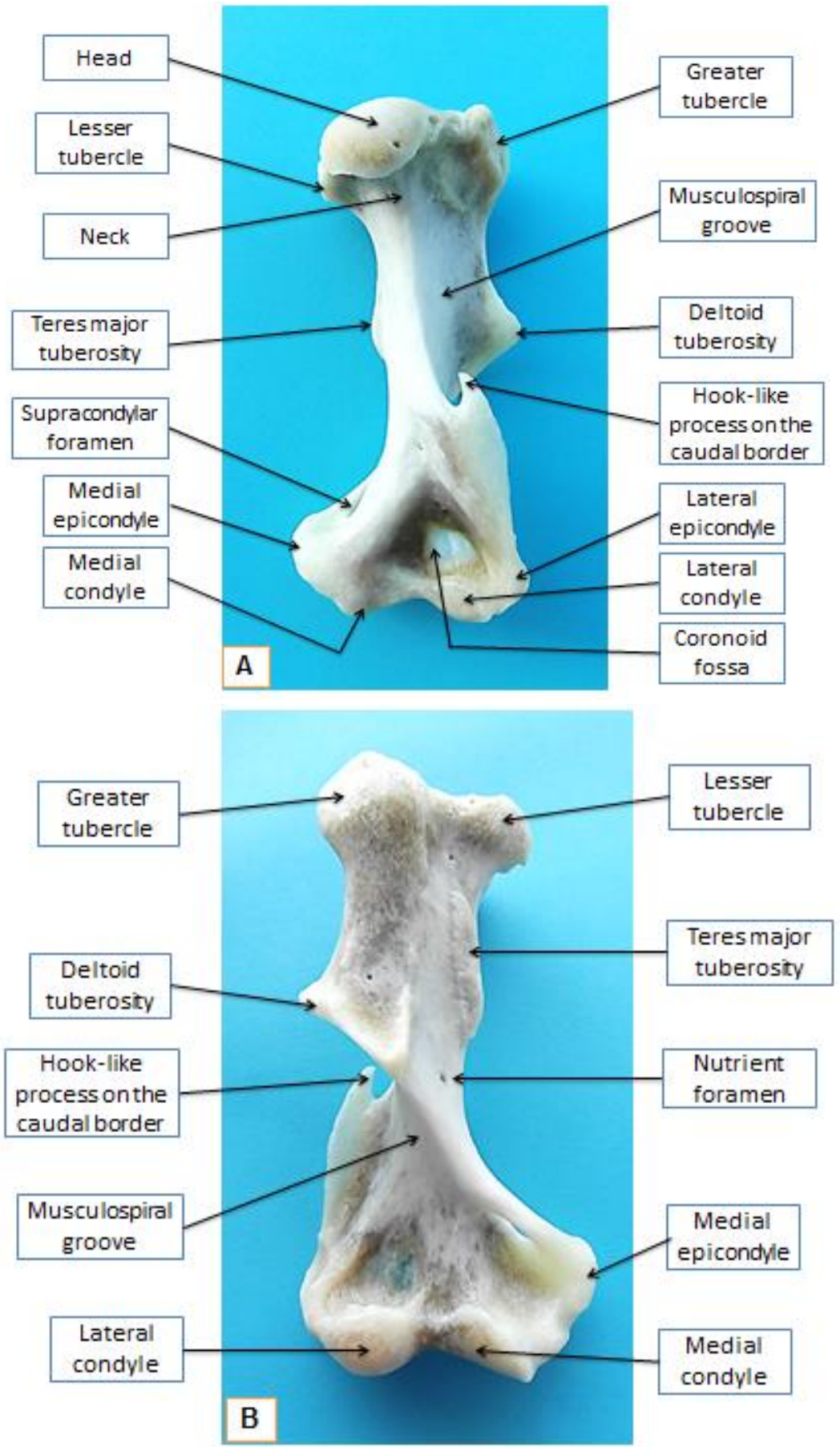

Fig (4): Humerus of Wombat; A) Cranial view, B) Caudal view, 


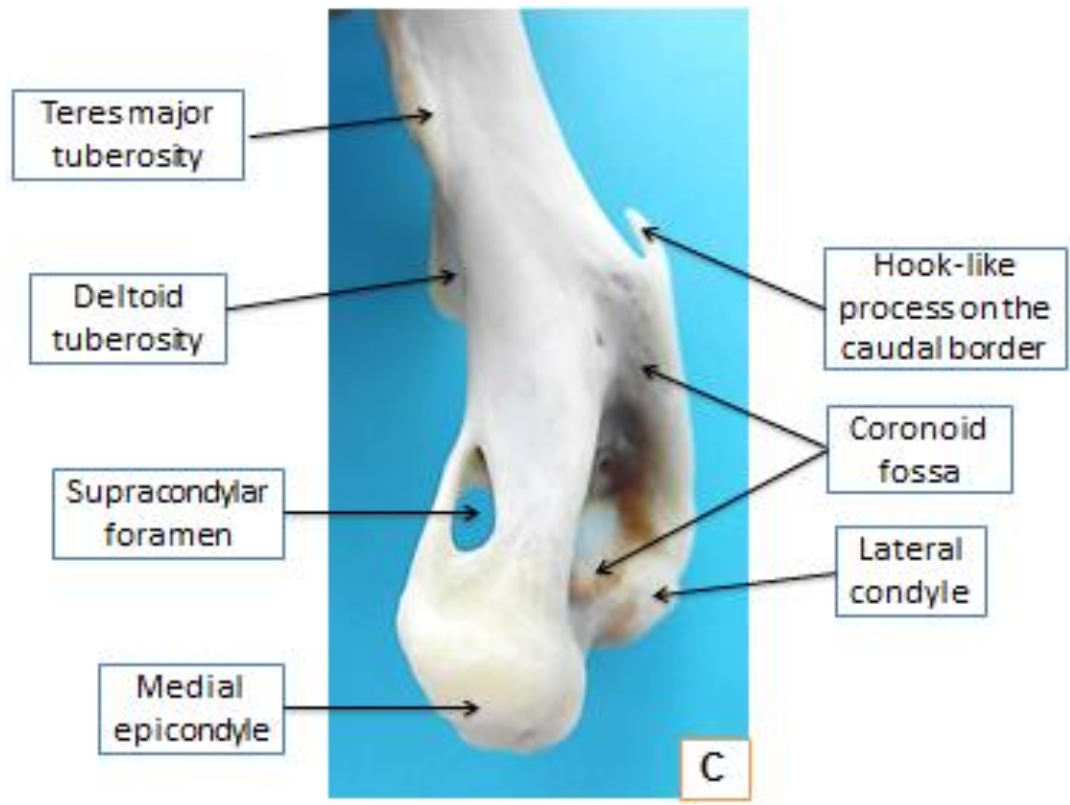

Fig (4): Humerus of Wombat; C) Medial view of the distal extremity.

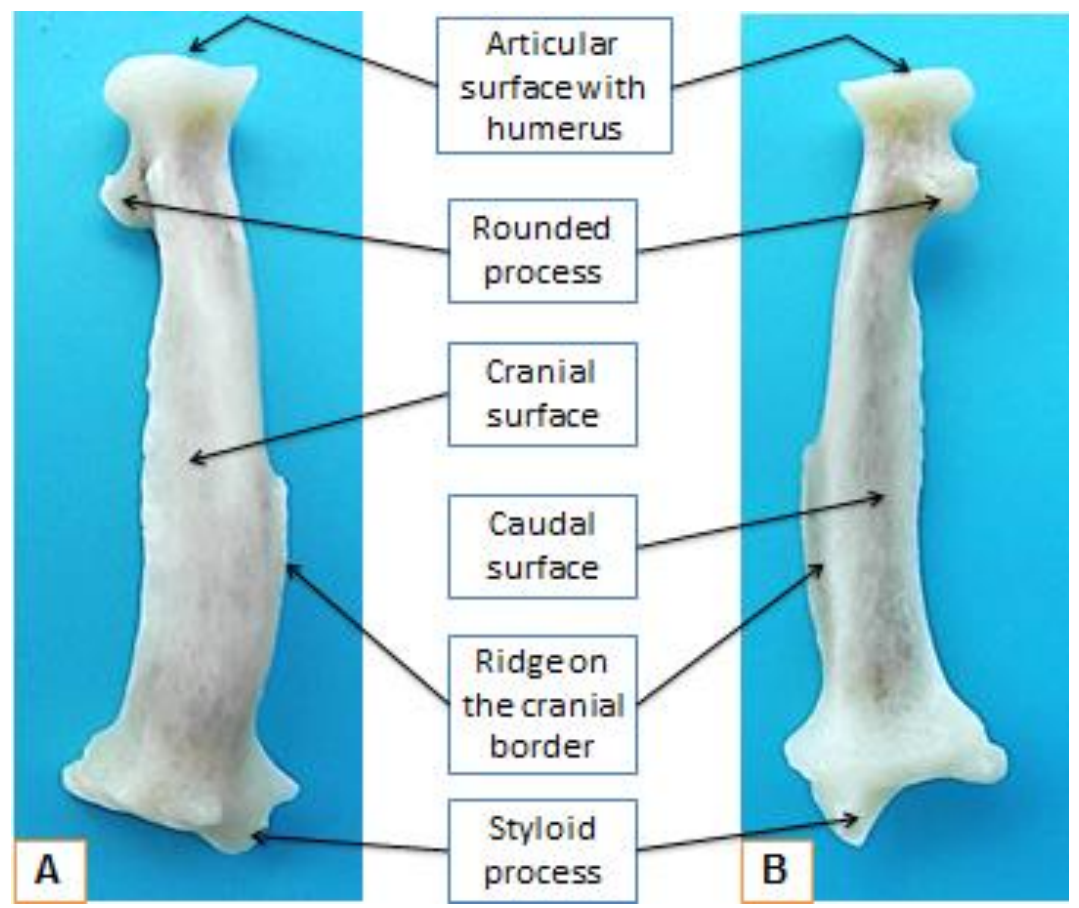

Fig (5): Radius of Wombat; A) Cranial view, B) Caudal view. 


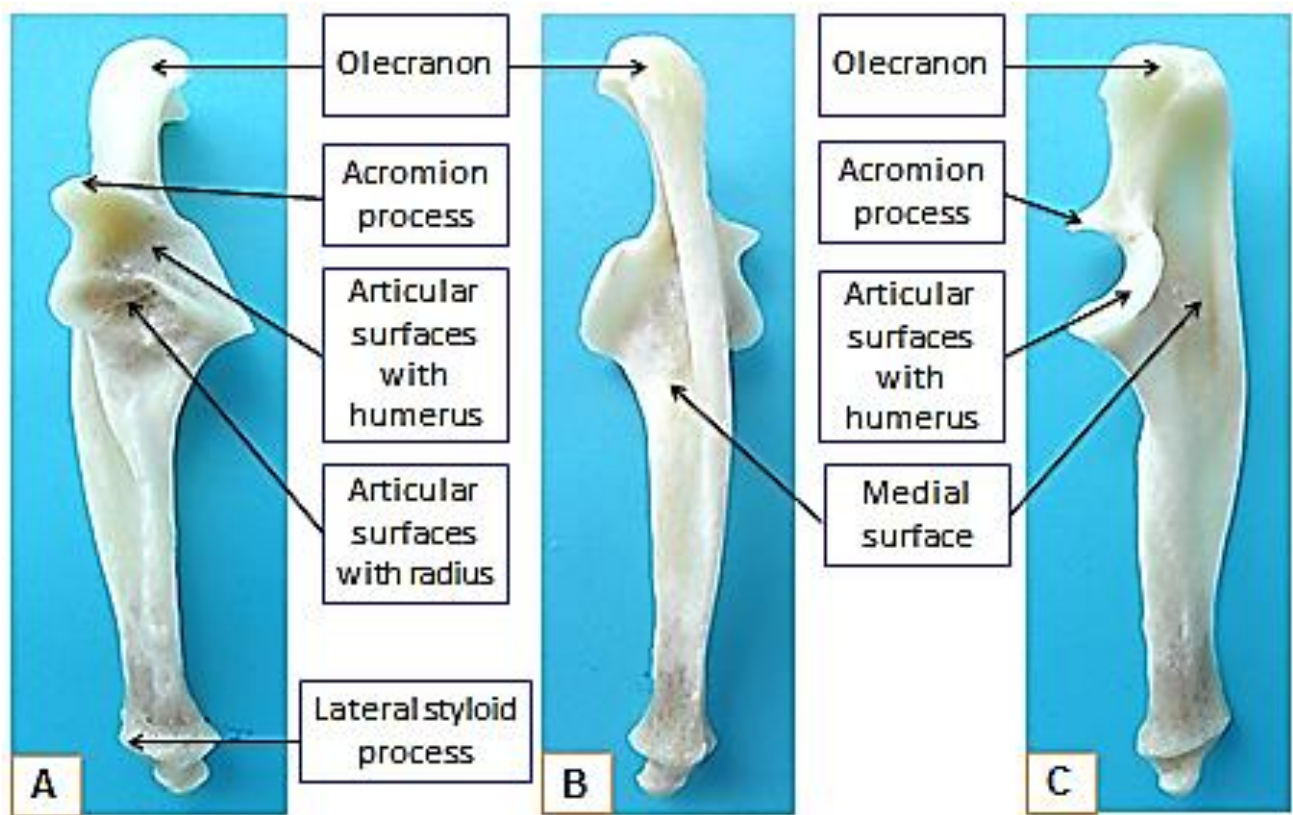

Fig (6): Ulna of Wombat A) Cranial view, B) Caudal view, C) Medial view.
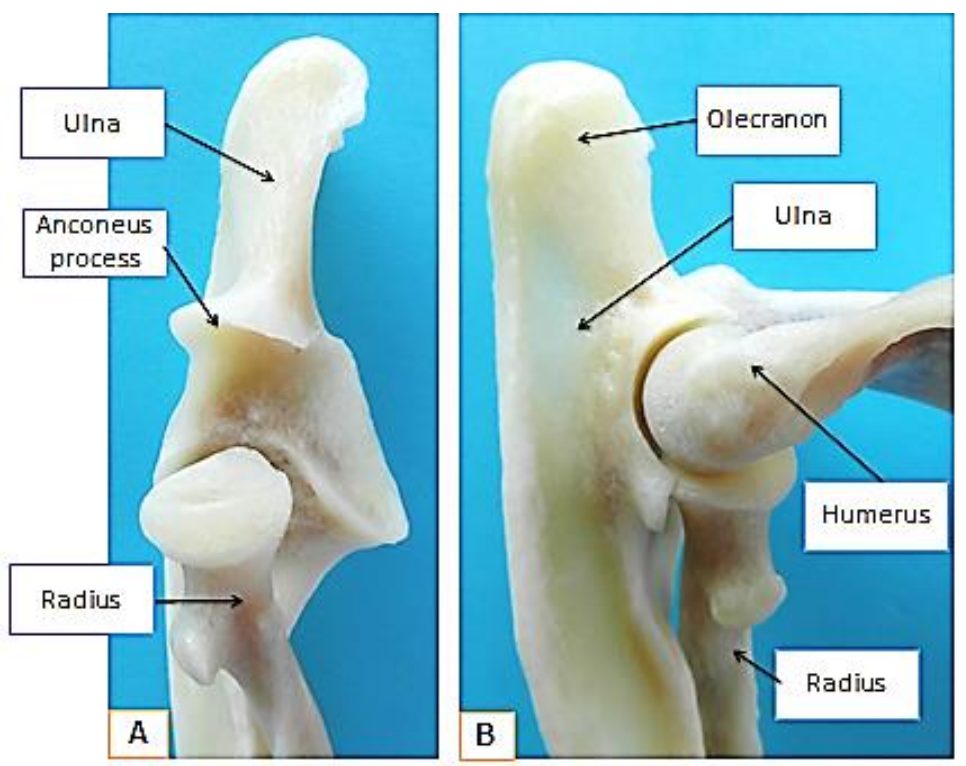

Fig (7): Proximal extremities of the Radius and Ulna of Wombat in a cranial view, showing the articular surfaces with the humerus (A). The articulation of the humeral condyles with the radius and ulna in a lateral view (B) 


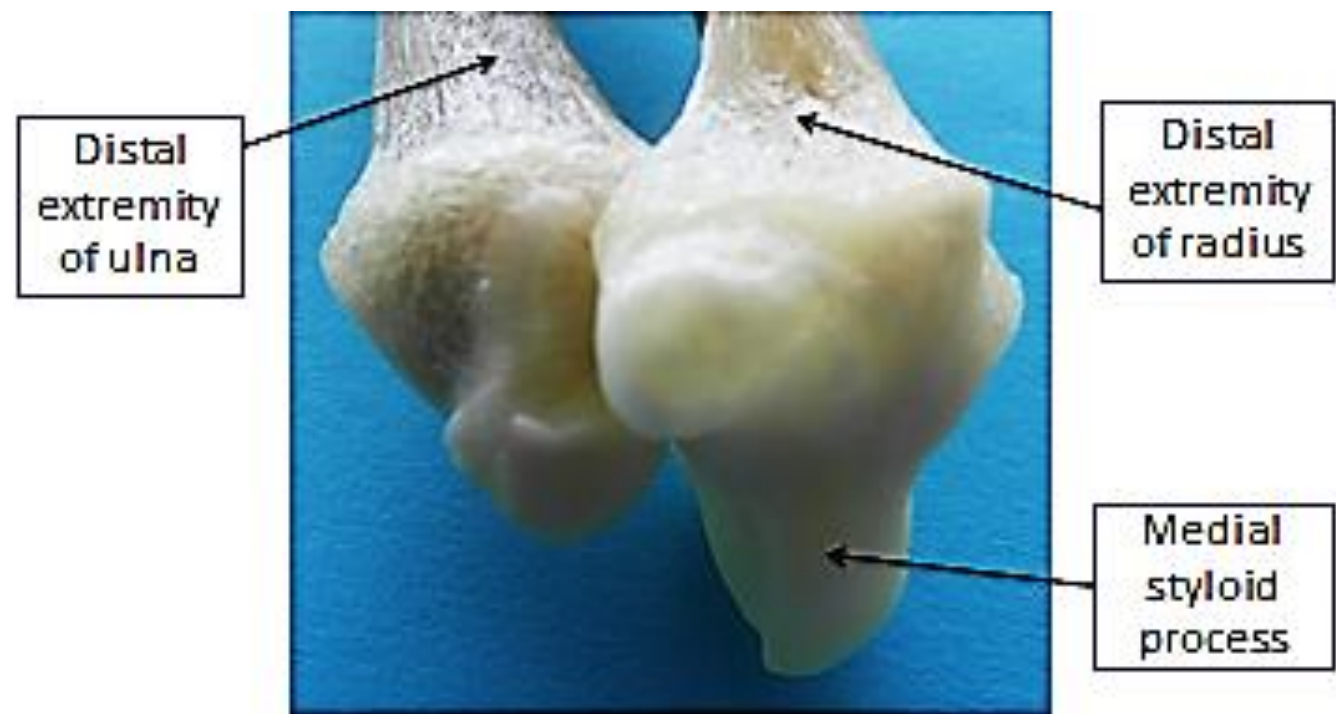

Fig (8): Distal extremities of the Radius and Ulna of Wombat in a cranial view

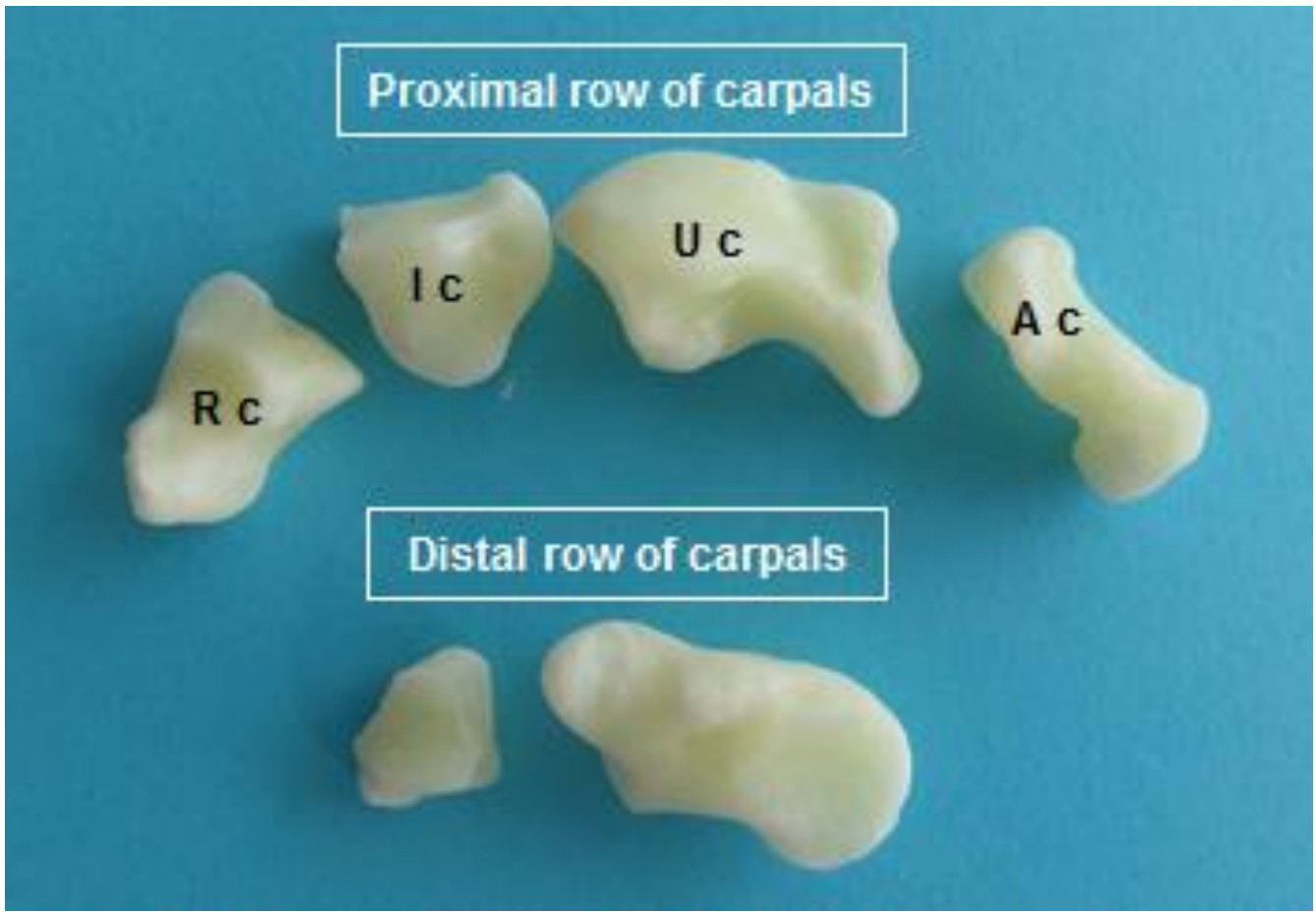

Fig (9): Right carpal bones of the wombat 


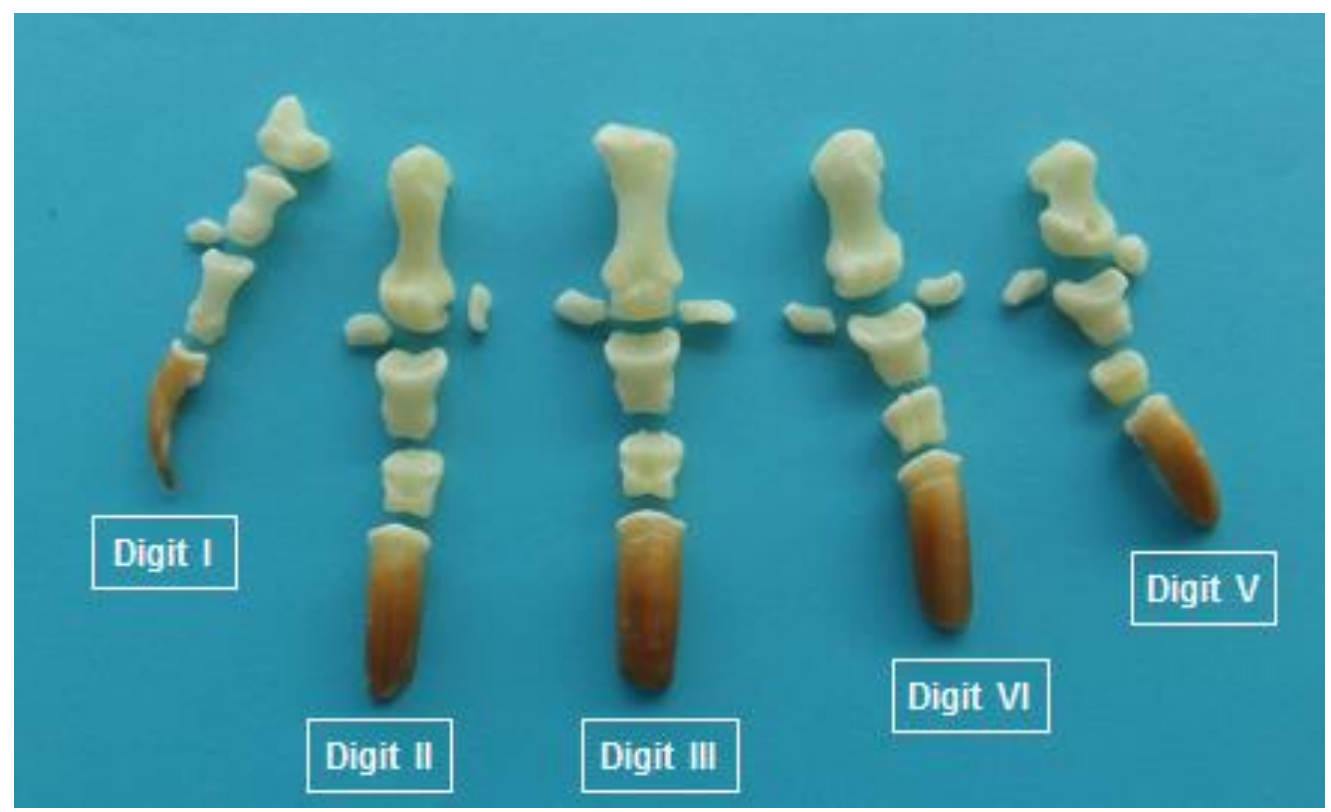

Fig (10): Right metacarpals and digits of the wombat 